\title{
Stage 4 Neuroblastoma
}

National Cancer Institute

\section{Source}

National Cancer Institute. Stage 4 Neuroblastoma. NCI Thesaurus. Code C6641.

Any primary tumor with dissemination to distant lymph nodes, bone, bone marrow, liver, skin, and/or other organs, except as defined for stage 4S. (cancer.gov) 